\title{
Abdominal obesity in adult Nigerian Africans: prevalence and co-occurrence with cardio-metabolic risk factors in a resource poor setting of a rural hospital in Eastern Nigeria
}

\author{
Gabriel Uche Pascal Iloh ${ }^{1, ~}$, Augustin Obiora Ikwudinma \\ ${ }^{1}$ Department of Family Medicine, Federal Medical Centre, Umuahia, Abia state, Nigeria \\ ${ }^{2}$ Department of Family Medicine, Federal Teaching Hospital Abakiliki, Nigeria
}

Email address:

ilohgup2009@yahoo.com(G. U. P. Iloh)

\section{To cite this article:}

Gabriel Uche Pascal Iloh, Augustin Obiora Ikwudinma. Abdominal Obesity in Adult Nigerian Africans: Prevalence and Co-Occurrence with Cardio-Metabolic Risk Factors in a Resource Poor Setting of a Rural Hospital in Eastern Nigeria. American Journal of Health Research. Vol. 1, No. 3, 2013, pp. 73-80. doi: 10.11648/j.ajhr.20130103.16

\begin{abstract}
Background: Abdominal obesity is socially and culturally not recognized as a health problem in Nigeria. However, the deleterious effects of abdominal obesity are on the cardio-metabolic disorders such as hypertension, dysglycaemia and dyslipidaemia. Of great concern in rural Nigeria is that most adult patients with abdominal obesity are not routinely diagnosed and therefore do not receive appropriate management Aim: This study was designed to determine the prevalence of abdominal obesity in adult Nigerian Africans and its co-occurrence with cardio-metabolic risk factors in a resource poor setting of a rural hospital in Eastern Nigeria Methods: This was a descriptive study carried out from June 2008 to June 2011. A total of 3012 adult patients aged 18-91 years were screened for abdominal obesity using the third report of National Cholesterol Education Panel(NCEP) in adult (ATP III) criterion and 350 patients who had WC $\geq 102 \mathrm{~cm}$ and $\geq 88 \mathrm{~cm}$ for men and women respectively were screened for cardio-metabolic risk factors. Hypertension, diabetes mellitus and dyslipidaemia were defined using JNC 7, American Diabetic Association and the third report of NCEP in adult (ATP III) criteria respectively. The data collected included basic demographic variables, blood pressure, waist circumference, and fasting lipid profile and plasma glucose. Results: .The prevalence of abdominal obesity was $11.6 \%$. The most common co-occurring primary cardio-metabolic risk factor was hypertension (44.6\%). Others included isolated dyslipidaemia(22.6\%) and diabetes mellitus(7.1\%). Conclusion: Abdominal obesity exists among the study population and co-occurred with cardio-metabolic risk factors with hypertension being the most frequent and diabetes the least. Abdominal obesity should be considered during clinical encounter with adult Nigerians in the study area alongside the complex of other primary cardio-metabolic risk factors.
\end{abstract}

Keywords: Abdominal Obesity, Adult Nigerians, Co-Occurring Cardio-Metabolic Risk Factors, Rural Hospital

\section{Introduction}

Abdominal obesity is socially acceptable among Nigerian Africans and therefore is not usually recognized as a health risk. [1-3] It is a medical problem in which excess fat has accumulated in the abdomen to the extent that it may have an adverse effect on health and/or increase medical problems. [1,2] It was once thought the health problem of affluent advanced countries but now exists in Nigeria in varying prevalence ranges and has been described as a time bomb for the future explosion in the frequency of dysmetabolic syndrome.[1,4,5] Globally, in the past, abdominal obesity was viewed as a sign of wealth and prosperity.[1,6] However, in the present, public perceptions of healthy body shape and weight have changed significantly since the beginning of the epidemic of obesity. [6-8] Normal adiposity of the abdomen(flat abdomen) is viewed as the ideal abdominal adiposity in western societies in contrast to the perception in traditional Nigerian societies where protruding abdomen(abdominal obesity) is culturally perceived as a symbol of good health and wealth.[1,3,5]

Obesity is defined using waist circumference (WC) criterion as an excess of adipose tissues resulting in waist 
circumference $\geq 102 \mathrm{~cm}$ ( 40 inches) and $\geq 88 \mathrm{~cm}$ ( 35 inches) for men and women respectively.[1,9] Similarly, abdominal overweight refers to the waist circumference between 94$101 \mathrm{~cm}$ and $80-87 \mathrm{~cm}$ for men and women respectively.[1,9] Many methods of estimating abdominal obesity have been developed and include imaging techniques such as computed tomography scan and magnetic resonance imaging. Although, the imaging methods are the gold standard for assessing abdominal adiposity, they are expensive for large scale epidemiological studies. [1] Waist circumference is therefore one of the most popular measure of abdominal adiposity and the simplest anthropometric indices of abdominal obesity. [1,2] The validity of WC as a measure of abdominal obesity is further supported by its association with obesity-related risk factors $[1,7,10]$ and a crucial correlate of metabolic syndrome. [11] The waist circumference therefore provides an easy method of describing pattern of abdominal adiposity even if the body mass index is about right. [5,12] The metabolic and structural changes in obese individuals are most often seen in abdominal obesity $[1,13]$ and have consistently been related to increased risk of coronary heart disease in men[14] and women.[15]

The prevalence of obesity as defined by waist circumference in the developing nations such as Nigeria is changing. [1,2,4,5] Ongoing nutritional, socio-economic and demographic, lifestyle and epidemiologic changes in Nigeria have contributed to the burden of abdominal obesity and its metabolic co-morbidities.[1,5,16, 17] The prevalence of abdominal obesity has been reported within and across populations in Nigeria[ $1,2,5,18]$ and other parts of the world such as United States of America,[19], South Korea [20] and Cotonou, Benin Republic.[21] In Nigerian Africans a prevalence of $50.8 \%$ was reported among geriatric hypertensives in Amurie Omanze, Imo state[1]; $21.7 \%$ was reported in selected rural and urban communities of Abia state, Nigeria;[5] 31.7\% was reported in Okirika, Rivers state, Nigeria;[2] $16.9 \%$ was reported in Port Harcourt, Nigeria, [2] and $33.8 \%$ was reported in Ogbomoso, Western, Nigeria.

Abdominal obesity occurring in adult population over a prolonged period may constitute a strong risk factor for cardio-metabolic and diverse chronic medical conditions.[1,19,22-24] The waist circumference anthropometry therefore provides guidelines on the identification, evaluation and treatment of adults who are abdominally obese. $[1,24]$ According to the International Diabetes Federation (IDF), abdominal obesity is a major independent risk factor for atherosclerotic cardiovascular diseases and appears to interact with or amplify the effects of other cardio-metabolic risk factors under the umbrella term of metabolic syndrome.[25]

In Nigeria, abdominally obese patients frequently present to the clinicians in rural hospitals of the country.[1,2] The failure to diagnose abdominal obesity by clinicians leads to missed opportunities to counsel these patients on lifestyle modifications and also to screen them for co-occurring metabolic risk factors. The enormous and rising burden of obesity [26-28] especially abdominal obesity[1,2,5] and its medical consequences in Nigeria has informed the decision for this study in a rural hospital setting. The early recognition of abdominal obesity by clinicians working in rural hospitals is quintessential to its management whilst identifying its co-occurring co-morbidities avails great opportunities for prevention and control. It was against this background that the authors were motivated to determine the prevalence of abdominal obesity in adult Nigerian Africans and its co-occurrence with cardio-metabolic risk factors in a resource poor setting of a rural hospital in Eastern Nigeria.

\section{Materials and Methods}

\subsection{Ethical Imperatives}

Ethical certificate was obtained from the Ethics Committee of the hospital. Informed consent was also obtained from respondents included in the study.

\subsection{Design}

This was a hospital-based descriptive study carried out from June 2008 to June 2011. A total of 3012 consecutive adult patients aged 18-91 years were screened for abdominal obesity using the third report of National Cholesterol Education Panel(NCEP) in adult (ATP III) criterion[29] and 350 abdominally obese patients who had WC $\geq 102 \mathrm{~cm}$ and $\geq 88 \mathrm{~cm}$ for men and women respectively were screened for cardio-metabolic risk factors.[1,9] Hypertension, diabetes mellitus and dyslipidaemia were defined using JNC 7,[1,30] American Diabetic Association[1,31] and the third report of NCEP in adult (ATP III) $[1,29]$ criteria respectively.

\subsection{Setting}

Amurie-Omanze is a rural community in Imo State, South-East Nigeria. Imo State is endowed with abundant mineral and agricultural resources with supply of professional, skilled, semi-skilled and unskilled manpower. Economic and social activities are low compared to industrial and commercial cities such as Onitsha, Port Harcourt and Lagos in Nigeria.

St Vincent De Paul Hospital is a rural Mission General Hospital in Imo state, South-east Nigeria and renders twenty four hours service daily including public holidays to the community.

\subsection{Sample size Determination}

Sample size estimation was determined using the formula [32] for calculating minimum sample size for descriptive studies: $N=Z^{2} p q / d^{2}$ where $N=$ Minimum sample size, $Z=$ Standard normal deviation usually set at 1.96 which corresponds to $95 \%$ confidence interval, $\mathrm{P}=$ Proportion of the population estimated to have a particular characteristic. 
Proportion was taken from previous study in Ogbomosho, South-west Nigeria[18] $=33.8 \%$ (0.33). $\mathrm{q}=1.0-\mathrm{p}=1.0$ $0.33=0.66, \mathrm{~d}=$ degree of accuracy set at 0.05 . Hence $\mathrm{N}=$ $(1.96)^{2} \times 0.33 \times 0.66 /(0.05)^{2}=343$. Therefore, $\mathrm{N}=343$. However, a total of 350 respondents were used based on the time frame for the study.

\subsection{Inclusion and Exclusion Criteria}

The adult patients aged 18 years and above who gave informed consent and met the selection criteria were consecutively screened for abdominal obesity and its cooccurring cardio-metabolic co-morbidities. Critically ill patients, pregnant women, women in pueperium, patients with demonstrable ascites and intra-abdominal masses determined by history and physical examination were excluded from the study.

\subsection{Diagnostic Procedures for Co-Occurring Cardio- Metabolic Risk Factors}

Co-occurring cardio-metabolic risk factors were evaluated by anthropometric measurement of waist circumference, clinical assessment of blood pressure and laboratory determination of fasting plasma glucose and lipid profile.

The waist circumference was measured using flexible non-stretchable tape.[1] The subject stood erect with arms at the side and feet together. The researcher faced the subject. The iliac crest and lower rib cage were first identified by palpation. The waist circumference was taken as the midpoint between the lower border of lower rib cage and iliac crest in a horizontal plane parallel to the floor.[1]

The blood pressure was measured using auscultatory method with standard mercury in glass Accuson sphygmomanometer.[1,26-28] Prior to the measurement, the patient was seated and rested for 5 minutes[33] in sitting position on a chair that supported the back comfortably. The left arm muscles were relaxed and the forearm was supported with the cubital fossa at the heart level. A cuff of suitable size was applied evenly to the exposed arm. The cuff was rapidly inflated until the manometer reading was about $30 \mathrm{mmHg}$ above the level at which the pulse disappeared and then slowly deflected. During this time, the Korotkoff sounds were monitored using a Litman stethoscope placed over the brachial artery. The systolic blood pressure was noted at the pressure at which the first heart sounds were heard(Korotkoff phase I). The diastolic blood pressure was taken as the pressure at the point when the heart sounds disappeared(Korotkoff phase v). The blood pressure was also measured in the right arm as described for the left arm in order to rule out significant inter-arm blood pressure difference and the arm that gave the higher reading was subsequently used. [33]

The blood glucose was determined after an overnight fast between 8.00 hours to 10.00 hours using venous plasma by glucose oxidase method.[1] A repeat fasting plasma glucose was done for those who had abnormal fasting plasma glucose test result on the next scheduled clinic visit.

After an overnight fast between 8.00 hours to 10.00 hours fasting venous blood sample was drawn from the patient after adequate disinfection of the skin over the venepuncture site and was separated to obtain the plasma.[1] Chemical analysis for the fasting lipid profile estimations was done at Hi-Tech laboratory, Owerri . The fasting lipid profile: total cholesterol, triglycerides and high density lipoprotein cholesterol were determined by enzymatic method according to the manufacturer's guide. The value of low density lipoprotein cholesterol (LDL-C) was calculated by using Friedwald's formula.[1,26]

\subsection{Diagnostic Criteria for Co-Occurring Cardio- Metabolic Risk Factors}

Abdominal overweight was defined as waist circumference from $94 \mathrm{~cm}$ to $101 \mathrm{~cm}$ for men and $80 \mathrm{~cm}$ to $87 \mathrm{~cm}$ for women while abdominal obesity was defined as waist circumference $\geq 102 \mathrm{~cm}$ and $\geq 88 \mathrm{~cm}$ for men and women respectively.[1,9]

Blood pressure readings were based on the JNC 7 classification and guidelines.[1,26,30] Hypertension was defined as systolic and/or diastolic blood pressure $\geq 140 / 90$ $\mathrm{mmHg}$ or documented use of antihypertensive medications in a previously diagnosed person with hypertension.[1,2628,30]

Diabetes mellitus was defined based fasting venous plasma glucose of $\geq 126 \mathrm{mg} / \mathrm{dL}$ which was confirmed by a repeat test on second clinic visit or current use of antidiabetic medications.[1,26-28,31]

Dyslipidaemia was defined according to The Third Report of the Expert Panel on Detection, Evaluation and Treatment of high blood cholesterol in adults (ATP III) $[1,26-29]$ as follows: total serum cholesterol $\geq 200 \mathrm{mg} / \mathrm{dL}(5.17 \mathrm{mmol} / \mathrm{L}) \quad$ and $/$ or triglyceride $\geq 150 \mathrm{mg} / \mathrm{dL} \quad(1.7 \mathrm{mmol} / \mathrm{L})$ and $/$ or low density lipoprotein cholesterol $\geq 100 \mathrm{mg} / \mathrm{dL}(2.58 \mathrm{mmol} / \mathrm{L})$ and $/$ or high density lipoprotein cholesterol $<40 \mathrm{mg} / \mathrm{dL}(<1.03 \mathrm{mmol} / \mathrm{L})$.

\section{Methods}

Data collection instrument had two sections: The basic demographic variables of age, sex, marital status, education, occupation, social class and clinical data collection section which contained information on clinical parameters such as waist circumference and blood pressure measurements, plasma glucose and lipid profile estimations. The social classification of patients was divided into lower, middle and upper occupational classes to suit Nigerian environment [28]

\subsection{Operational Definitions}

The researchers defined adult patients as those age 18 years and above.[26-28] Cardio-metabolic risk factors are umbrella term for metabolic risk factors of cardiovascular 
diseases such as hypertension, diabetes mellitus, obesity and dyslipidaemia.[11,28]

\subsection{Statistics}

The results generated were analyzed using software Statistical Package for Social Sciences (SPSS) version 13.0, Microsoft Coperation Inc. Chicago, IL, USA for the calculation of percentages for categorical variables and mean for continuous data.

\section{Results}

Of the 3012 adult patients screened for abdominal obesity, three hundred and fifty were abdominally obese giving prevalence of $11.6 \%$. One thousand, one hundred and seventy four $(39.0 \%)$ had pre-abdominal obesity (overweight abdominal adiposity) while one thousand, four hundred and eighty-eight (49.4\%) had normal abdominal adiposity.[Table 1]

Table 1: Distribution of the study population based on abdominal adiposity

\begin{tabular}{ll}
\hline Parameter & Number (\%) \\
\hline $\begin{array}{l}\text { Normal abdominal adiposity } \\
\text { Pre-abdominal obesity(overweight } \\
\text { abdominal adiposity) }\end{array}$ & $1488(49.4)$ \\
Abdominal obesity & $1174(39.0)$ \\
Total & $350(11.6)$ \\
\hline
\end{tabular}

The age of the study population ranged from 18 years to 91 years with mean age of $48 \pm 10.1$ years. There were one hundred and fifty four (44.0\%) males and one hundred and ninety six $(56.0 \%)$ females with male to female ratio of $1: 1.3$. Higher proportions of the study population were married (66.6\%), two hundred and seventy $(77.1 \%)$ had secondary education and more, one hundred and seven $(30.6 \%)$ were peasant farmers while two hundred and eighty five (81.4\%) belonged to lower social class [Table 2].

Table 2: Basic demographic profile of the study population

\begin{tabular}{ll}
\hline Parameter & Number(\%) \\
\hline Age(years) & $36(10.3)$ \\
$18-39$ & $183(52.3)$ \\
$40-60$ & $131(37.4)$ \\
$>60$ & $350(100.0)$ \\
Total & \\
Sex & $154(44.0)$ \\
Male & $196(56.0)$ \\
Female & $350(100.0)$ \\
Total & \\
Marital status & $15(4.3)$ \\
Single & $233(66.6)$ \\
Married &
\end{tabular}

\begin{tabular}{ll}
\hline Parameter & Number(\%) \\
\hline Widowed & $94(26.8)$ \\
Separated & $8(2.3)$ \\
Total & $350(100.0)$ \\
Education & \\
Primary and less & $80(22.9)$ \\
Secondary and more & $270(77.1)$ \\
Total & $350(100.0)$ \\
Occupation & \\
Unemployed & $36(10.3)$ \\
Student/Apprentice & $12(3.4)$ \\
Public/civil servants & $39(11.1)$ \\
Farming & $107(30.6)$ \\
Trading & $46(13.1)$ \\
Artisans & $48(13.7)$ \\
Driving & $8(2.3)$ \\
Clergy & $11(3.1)$ \\
Retirees & $43(12.4)$ \\
Total & $350(100.0)$ \\
Social class & \\
Lower class & $285(81.4)$ \\
Middle class & $47(13.4)$ \\
Upper class & $18(5.2)$ \\
Total & $350(100.0)$ \\
\hline
\end{tabular}

The most common co-occurring cardio-metabolic risk factor was hypertension (44.6\%), Others included isolated dyslipidaemia(22.6\%) and diabetes mellitus(7.1\%)[Table 3]

Table 3: Frequency of the co-occurring primary cardio-metabolic risk factors among the study population

\begin{tabular}{ll}
\hline Parameter & Number (\%) \\
\hline Hypertension & $156(44.6)$ \\
Yes & $194(55.4)$ \\
No & $350(100.0)$ \\
Total & \\
Lipid profile & $271(77.4)$ \\
Normal & $79(22.6)$ \\
At least one lipid abnormality & $350(100.0)$ \\
Total & \\
Diabetes mellitus & $25(7.1)$ \\
Yes & $325(92.9)$ \\
No & $350(100.0)$ \\
\hline
\end{tabular}

\section{Discussion}

The prevalence of abdominal obesity of $11.6 \%$ in this study is less than $31.7 \%$ reported among adult patients in a rural hospital in Okrika, Rivers State, South-south 
Nigeria,[2] 21.7\% reported in Abia State, South-east Nigeria,[5] 33.8\% reported in Ogbomoso, South-west Nigeria [18] and $32.0 \%$ reported in Cotonou, Benin Republic. [21] The finding of this study has buttressed the reports that abdominal obesity is an issue of phenomenal medical importance in Nigeria [1,2,5] and in other parts of the world such as Cotonou, Benin Republic, [21] United States of America[19] and Jamaica[22] This study has demonstrated that abdominal obesity is no longer the disease of affluent countries and has corroborated the reports that abdominal obesity exist in Nigeria in variable proportions.[1,2,5] The abdominal obese condition could predispose the patients to increase cardio-metabolic morbidity and mortality.[22,28] This study therefore creates a pedestal for the adult patients in the study area to understand abdominal obesity as a health risk not an indication of prosperity that can be reduced through lifestyle modifications involving healthy diet, adequate exercise among other diverse interventions. It is therefore pertinent to detect early the development of abdominal obesity [34] particularly among the study population as early intervention may alter morbidity end points. Educating these patients on the relevance of waist size determination and its interpretation should be integrated as part of patient education during clinical encounter with abdominally obese patients in the study area.

The result of this study has shown that the most common co-occurring primary cardio-metabolic risk factor of abdominal obesity was hypertension(44.6\%). This finding is in consonance with the reports of the co-occurrence of hypertension among abdominally obese patients in Okirika, South-south Nigeria, [2] Ogbomoso, South-west Nigeria.[18], United States of America[22,23] and Jamaica[22] Patho-genetically, the mechanism linking obesity to hypertension has been elucidated in medical literature.[35-37] However obesity may lead to hypertension by activating the rennin-angiotensinaldosterone system and stimulating sympathetic activity, promoting leptin resistance by increased pro-coagulatory activity, causing endothelial dysfunction and subclinical inflammation.[37] Further mechanism includes increased renal sodium reabsorption leading to a shift to the right of the pressure natriuresis relationship thereby resulting in volume expansion.[37] These patho-physiological mechanisms therefore have untoward effects on the cardiovascular system thus magnifying the burden of hypertension on obesity.[37] While abdominally obese patients are prone to hypertension, hypertensive patients also appear to be prone to abdominal obesity. It is therefore likely that abdominal obesity, hypertension and other metabolic abnormalities interact and potentiate their individual impact on cardiovascular system. However, in patients with abdominal obesity who develop hypertension, the prognosis worsens compared to those without hypertension and the cost of care invariably increases when hypertension co-occur with abdominal obesity. The strategies to reduce the risk of hypertension in adult patients with abdominal obesity in the study area should therefore focus on control of abdominal obesity amongst other diverse modifiable metabolic and behavioural cardiovascular risk factors.

The finding of this study has shown that dyslipidaemia co-exist with abdominal obesity (22.6\%) among study population. The finding of this research has given credence to the reports that dyslipidaemia is becoming an important medical condition among abdominally obese patients in Nigeria[1,2.5] and other parts of the world such as United States of America[19] and are linked with other clustering of metabolic risk factors referred to as metabolic syndrome.[11] Although plasma lipids are essential for physiological functions of the body but abnormal levels cause increase in cholesterol gradient leading to increase sequestration of cholesterol into the abdominal sites or reduction in the ability of the body to shift cholesterol from abdominal tissues to the liver.[38] Moreover, abdominal fats are more sensitive to lipolytic hormones which increase the release of free fatty acids in the abdominal adipose tissues. The free fatty acids released cause hypertrophy of the abdominal adipose tissues and also provide additional substrate for the synthesis of triglycerides by the liver which results in dyslipidaemic profile associated with abdominal obesity.[38,39] However, not all abdominally obese patients do develop dyslipidaemia, but their chances of developing dyslipidaemia are higher. This may be promoted and enhanced by other constitutional and nonconstitutional cardiovascular risk factors.[40,41] Screening for dyslipidaemia in abdominal obesity need to be at diagnosis as the development and damage by dyslipidaemia start even before the diagnosis is made and this will enable clinicians ensure that abdominally obese patients with atherogenic dyslipidaemia receive the life saving benefits of lipid lowering therapy in addition to lifestyle modifications.

Twenty-five $(7.1 \%)$ of the abdominally obese patients in this study has concomitant diabetes mellitus. The finding has supported the reports that described abdominal obesity as a risk factor for diabetes mellitus.[1,19,22] Pathophysiologically, several mechanisms are involved in the development of diabetes mellitus in obese individuals. [19,22,42-45] Protein hormones produced in adipose tissues with other mediators have been shown to have effects in regulating body weight in human beings.[43,45] High circulating leptin concentrations in obesity may cause insulin resistance by inhibiting insulin signalling. [43,45] More so, other mediators such as adipokines, resistin and adiponectins are linked between obesity and diabetes mellitus.[43,45] In addition, the free fatty acids released as a consequence of the lipolytic activities of the abdominal adipocytes are more resistant to the action of insulin leading to peripheral insulin resistance which is a feature of diabetes mellitus among obese patients. The increase in number of fat cells alters body's response to insulin, potentially leading to insulin resistance that result in the development of type 2 diabetes mellitus.[43-45] Identifying 
the co-occurring diabetes mellitus in abdominally obese patients therefore avails greater opportunities for appropriate health information, education, communication and health promotion for the patients.

Study implications: As the case detection of abdominal obesity increases daily among adult Nigerians in rural hospitals, screening for its primary cardio-metabolic risk factors is an important health care challenge that is often neglected in rural and remote health care. Of great concern in rural Nigeria is that most adult patients with abdominal obesity are not routinely screened for co-occurring cardiometabolic risk factors and therefore do not receive appropriate management. Although not all adult patients with abdominal obesity develop other constellation of cardio-metabolic disorders but their chances of developing them are higher. Abdominal obesity and its co-occurring cardio-metabolic disorders could add to other driving forces responsible for increasing predisposition to cardiovascular endpoints such as coronary heart disease and stroke. Although some adult Nigerians in rural hospitals may be familiar with their waist sizes, clinicians should therefore teach them how to determine their waist circumferences and the importance of screening for cardiometabolic risk factors. The earlier in the pre-morbid phase, abdominal obesity and cardio-metabolic risk factors are detected in adult Nigerians, the better the prognosis and outcome of management. Establishing a baseline for these measurements and checking them during subsequent patient visits appropriately can provide clinicians with an excellent means of educating their adult patients with abdominal obesity on lifestyle modifications and other diverse clinical care.

Study limitations: The limitations imposed by the descriptive nature of the study are recognized by the researchers. However, this study stimulates the need for analytical and longitudinal studies on the co-occurrence of abdominal obesity with primary cardio-metabolic correlates. This would enable a quasi cause-effect relationship to be drawn and also for a reliable and valid conclusion to be ascertained. The waist circumference was taken at a single point in time and the authors had no information on previous measurements. In addition, the authors had no direct measures of abdominal fat or muscle composition. The researchers also anticipated measurement errors and biases for abdominal adiposity. However, there effects were reduced by using non-stretchable tape and training of the researchers. The training of the research team included standardization of measurement of waist circumference. This was to ensure accuracy and reliability and reduce inter- and intra-observer errors and ensure comparability of measurements. This study therefore provides useful baseline information on which subsequent interventions in the study area could be based and evaluated.

Conclusion: Abdominal obesity exist among adult Nigerians in the study area and co-occurred with primary cardio-metabolic risk factors with hypertension being the most frequent correlate and diabetes mellitus the least co- occurring condition. Anthropometric determination of abdominal obesity and screening for its co-occurring cardio-metabolic risk factors should be an essential part of clinical care framework for adult Nigerians attending secondary rural health facilities in the study area. This will invariably improve the quality of care received by these patients who are living in a resource constrained rural setting.

Acknowledgement

The authors are grateful to Rev. Sister Francisca Eya of St. Vincent de Paul hospital, Amurie-Omanze for permission for the study.

\section{References}

[1] Iloh GUP, Amadi AN, Njoku PU, Ofoedu JN, Awa-Madu J. The magnitude of abdominal adiposity and atherogenic dyslipidaemia among geriatric Nigerians with arterial hypertension in a rural hospital in south-eastern Nigeria. Niger J Clin Pract . 2012; 15: 462-468.

[2] Siminnialayi IM, Emem-Chioma PC, Dapper DV. The prevalence of obesity as indicated by BMI and waist circumference among Nigerian adult attending Family Medicine clinics as outpatients in Rivers state. Niger J Med 2008; 17:340-345.

[3] Okeke EC, Ibeh GN, Ene-Obong HN. Body weight perception among Igbo people in the University of Nigeria, Nsukka. Agro-Science Journal 2006; 5: 17-24.

[4] Abubakar AR, Lander W, Agyemang C, Jones M, Kirk A, Bhopal RS. Prevalence and time trends in obesity among adult West African populations: a meta-analysis. Obesity Reviews 2008; 9: 297-311.

[5] Chukwuonye II, Chuku A, Onyenoro UU, Okpechi IG, Madukwe OO, Umeizudike TI, Ogah OS. Prevalence of abdominal obesity in Abia State, Nigeria: results of a population-based house-to-house survey. Diabetes, Metabolic Syndrome and Obesity: Targets and Therapy 2013; 6: 285-291.

[6] Lean MEJ, Han TS, Seidell JC. Impairment of health and quality of life in people with large waist circumference. Lancet 1998; 351: 853-856.

[7] Doll S, Paccaud F, Hovet P, Bumier M, Wietlisbach V. Body mass index, abdominal adiposity and blood pressure: consistency of their association across developing and developed countries. Int J Obes 2002; 26: 48-57.

[8] Ziraba AK, Fotso JC, Ochako R. Overweight and obesity in urban Africa: A problem of the rich or the poor? BMC Public Health 2009; 9: 465.

[9] The European Food Information Council. The basics: Obesity and overweight.(Online). 2006. (cited 2008 March); Available from: URL: http://www.eufic.org/article/en/expid/basics-obesityoverweight $/$.

[10] Wahrenberg H, Hartel K, Leijonhufvud B. Waist circumference predicts insulin resistance. A retrospective study. BMJ 2005; 330: 1363-1364. 
[11] Tokin A. The metabolic syndrome: A growing problem. European Heart Journal Supplement 2004; 6: A32-A42.

[12] Janssen I, Katzmarzyk PT, Ross R. Waist circumference and not body mass index explains obesity-related health risk. Am J Clin Nutrb2004; 79: 379-384.

[13] Fezeu I, Balkau B, Kengne AP, Sobngwi E, Mbanya JC. Metabolic syndrome in a sub-Saharan African setting: central obesity may be the key determinant. Atheroclerosis 2007; 193: 70-76.

[14] Rexrode KM, Burning JE, Manson JE. Abdominal and total adiposity and risk of coronary heart disease in men. Int $\mathrm{J}$ Obes Relat Metab Disord 2001; 25: 1047- 1056.

[15] Rexrode KM, Carey VJ, Hennekens CH. Abdominal adiposity and coronary heart disease in women. JAMA 1998; 280: $1843-1848$.

[16] Adediran O, Akintude AA, Edo AE, Opadijo OG, Araoye AM. Impact of urbanization and gender on frequency of metabolic syndrome among native Abuja settlers in Nigeria. J Cardiovasc Dis Res 2012; 3: 191-196.

[17] Ekpenyong C, Akpan E. Contextual Trend in Preventing Obesity Epidemic in Developing Countries: Role of the Key Players. European Journal of Preventive Medicine. 2013; 1: 20-31

[18] Amole IO, OlaOlorun AD, Odegah LO, Adesina SA. The prevalence of abdominal obesity and hypertension amongst adults in Ogbomoso, Nigeria. Afr J Prm Health Care Fam Med 2011; 3.188.

[19] Okosun IS, Cooper RS, Prewitt TE, Rotimi CN. The relation of central adiposity to components of the insulin resistance syndrome in a biracial US population sample. Ethn Dis 1999; 9: $218-229$

[20] Park HS, Yun YS, Park JY, Kim YS, Choi JM. Obesity, abdominal obesity, and clustering of cardiovascular risk factors in South Korea. Asia Pac J Clin Nutr 2003;12: 411418

[21] Sodjinou R, Agueh V, Fayomi B, Delisle H. Obesity and cardio-metabolic risk factors in urban adults of Benin: relationship with socio-economic status, urbanization and lifestyle patterns. BMC Public Health 2008; 8:84.

[22] Okosun IS, Cooper RS, Rotimi CN, Osotimehin B, Forrester T. Association of waist circumference with risk of hypertension and type 2 diabetes in Nigerians, Jamaicans and African-Americans. Diabetes Care 1998; 21: 1836-1842.

[23] Okosun IS, Choi S, Dent MM, Jobin T, Dever GE. Abdominal obesity defined as a larger than expected waist girth is associated with racial/ethnic differences in risk of hypertension. J Hum Hypertens 2001; 15: 307-312.

[24] Okosun IS, Rotimi CN, Forrester TE, Fraser H, Osotimehin B, Muna WF, et al. Predictive value of abdominal abdominal obesity cut off points for hypertension in Blacks from West African and Carribean island nations. Int J Obes 2000; 24 180-186.

[25] Alberti KG, Zimmet P, Shaw J. Metabolic syndrome-a new world-wide definition. A consensus statement from the International Diabetes Federation. Diabet Med 2006; 23: 469-480.
[26] Iloh GUP, Amadi AN, Nwankwo BO, Ugwu VC. Obesity in adult Nigerians: A study of its pattern and common primary co-morbidities in a rural Mission General Hospital in Imo State, south-eastern Nigeria. Niger J Clin Pract 2011; 14: $212-218$

[27] Iloh GUP, Amadi AN, Nwankwo BO. Obesity in adult Nigerians: A study of its prevalence and common primary co-morbidities in a semi-urban Mission General Hospital in Imo State, south-eastern Nigeria. Niger J Med 2010; 19: 459 -466 .

[28] Iloh GUP, Ikwudinma AO, Obiegbu NP. Obesity and its cardio-metabolic co-morbidities among adult Nigerians in a Primary Care Clinic of a tertiary hospital in South-eastern Nigeria. J Fam Med Primary Care 2013; 2: 20-26.

[29] Executive summary of the third report of The National Cholesterol Education Programme(NCEP) Expert Panel on Detection, Evaluation and Treatment of high blood cholesterol in adults(Adult Treatment Panel III. JAMA 2001; 285: $2486-7$.

[30] Chobanian AV, Bakris GL, Black HR, Cushman WC, Green LA, Izzo JL et al. The seventh report of the Joint National Committee on Prevention, Detection, Evaluation and Treatment of high blood pressure: The JNC VII report. JAMA 2003; 289: 2560- 2572.

[31] American Diabetes Association: Diagnosis criteria for diabetes mellitus. Diagnosis and classification of diabetes mellitus. Diabetes Care 2010; 33(Suppl 1): S62-S69.

[32] Araoye MO. Sample size determination. Research Methodology with Statistics for Health and Social Sciences, Ilorin, Nathadex Publishers, 2004; p115- 121.

[33] Onwubere B, Kadiri S. Guidelines for the management of hypertension in Nigeria. Nigerian Hypertension Society. Enugu, Ezu Books Limited 2005.p. 1-40

[34] Ramos DC, Mehta R, De La Luz Castro J, Limones RC, Rubi EG, Aguilar-Salinas CA. Awareness of Abdominal Adiposity as a cardiometabolic Risk Factor(The 5A Study): Mexico. Diabetes Meta Syndr Obes 2011; 4: 107-117

[35] Ratimouni H. Leptin and the cardiovascular system. Res Horm Res 2004; 79: 224-244.

[36] Miyawaki T, Abe M, Yahata K, Kajiyama N, Katsuma H, Saito N. Contribution of visceral fat accumulation to the risk factors for atherosclerosis in non-obese Japanese. Intern Med 2004; 43: 1138-1144.

[37] Wofford MR, Hall JE. Pathophysiology and treatment of obesity hypertension. Curr Pharm Des 2004; 10:3621- 3637.

[38] Ito $\mathrm{H}$, Nakasuga $\mathrm{K}$, Ohshima A. Excess accumulation of body fat is related to dyslipidaemia in normal-weight subjects. Int J Obes Relat Metab Disord 2004; 28: 242-247.

[39] Njeleka MA, Negishi H, Nara Y, Sato T, Tomoshiro M, Kuga S. Obesity and lipid profiles in middle-aged Men and women in Tanzania. East Afr Med J 2002; 79:58-64.

[40] Iloh GUP, Chuku A, Obiegbu NP, Ofoedu JN, Ikwudinma AO. Frequency of cardiovascular risk factors in adult Nigerians with family history of non-communicable cardiovascular disease in a primary care clinic of a tertiary hospital in a resource-constrained environment of Eastern Nigeria. American Journal of Health Research 2013; 1: 17-25. 
[41] French SA, Story M, Jeffery RW. Environmental influences on eating and physical activity. Am Rev Public Health 2001; 22: 309-335.

[42] Han TS, Williams K, Suttar N, Hunt KJ, Lean ME, Haffner SM. Analysis of obesity and hyper Insulinaemia in the development of metabolic syndrome: San Antonio Heart study. Obes Res 2002; 10:923 - 931.

[43] Bates SH, Kulkarni RN, Seifert M, Myers MG Jr. Roles for leptin receptor/STAT3 - dependent and independent signals in the regulation of glucose homeostasis. Cell Metabolism 2005, 1:169- 178 .

[44] Miner JL. The adipoctye as an endocrine cell. J Anim Sci, 2004; 82: $935-41$.

[45] Oyekan AO. Genetics of food intake, body weight and obesity-Role of leptin. Niger Med Pract 2005; 47:108-112. 